\title{
SELF COMPACTING CONCRETE USING INDUSTRAIL WASTE MATERIALS
}

\author{
${ }^{1}$ Yash Paul Sachdeva, ${ }^{2}$ Prof.Sanjeev Naval, ${ }^{3}$ DrManjeet Bansal \\ 1student Of M.Tech Civil Engg.(Structure).Daviet,Jalandhar \\ 2associate Professor \&Head,Deptt.Of Civil Engineering,Daviet,Jalandhar \\ 3associate Professor, Deptt. Of Civil Engineering Ptu Giani Zail Singh Campus Bathinda
}

\begin{abstract}
A Self-compacting concrete(SCC)is the one that can be placed in the form and can go through obstruction by its own weight and without the need of vibration. The present thesis report is based on water/binder ratio below 0.30 and Fly ash based SCC with silica fume. The present investigation has been under taken to investigate the structure the property if SCC with fly ash and silica fume using water binder (W/b) ratio below 0.3. Several trial mixes were made in order to reach the suitable mix proportion so as to satisfy the criteria for making successful SCC. Test result include compressive strength, split tensile strength, flexural strength, ultrasonic Pulse Velocity and Rebound hammer values. The stress-strain curves for different mixes clearly depict that strain values for VMA/SCC were on the higher side as compared to strain values for Silica/SCC. Strain values for VMAJSCC were up to 0.0065 whereas for Silica/SCC, it was up to 0.0038 . Compressive strength curve pattern shows that there is uniform increase of compressive strength values for VMAJSCC to that Silica/SCC. Early age compressive strength (at 3 days and 7 days) of Silica/SCC was found more than VMA/SCC. Making 7 days compressive strength consideration, Silica/SCC was found in between 23.5 to $35.6 \mathrm{MPa}$ whereas for VMA/SCC, it was found in between 17.0 to 31.5 MPA. The Use of fly ash and silica fume normally reduces the environmental hazard but makes the concrete economical as well.
\end{abstract}

Keywords:-Compressive strength, Flexural strength, Spilit Tensile strength, Silica Fume, Fly ash

\section{INTRODUCTION}

A decade ago a group of researchers at the University of Tokyo succeeded in developing a mix that can be compacted into every corner of a formwork, purely by means of its own weight and without the need of vibratory compaction. This innovative mix is known as "self-compacting concrete" With increased requirements for both productivity and comfort on the job site as well as the performance of the hardened concrete, the use of SCC can reduce costly labor, accelerate construction timetables, and enable more flexibility. In placement operations and scheduling, as well as provide greater flexibility in using and procuring the required resources, resulting in both time and resource savings.

One of the major challenges of our present society is the protection of environment. Some of the important elements in this respect are the reduction of the consumption of energy and natural raw materials. Big attention is being focused on the environment and safeguarding of natural resources and recycling of wastes materials. In the last 20 years, a lot of work concerning the use of several kinds of urban wastes in building materials has been published. The use of different waste materials is showing prospective application in construction industry as alternative to conventional materials. Such practice conserves natural resources and reduces the space required for the landfill disposal of these waste materials. The present thesis report is based on water/binder ratio below 0.30 and Fly ash based SCC with silica fume. Silica fume, also referred to as micro silica or condensed silica fume, is another material that is used as an artificial pozzolanic admixture. It is a product resulting from reduction of high purity quartz with coal in an electric arc furnace in the manufacture of silicon or ferrosilicon alloy. Silica fume rises as an oxidized vapor. It cools, condenses and is collected in cloth bags. It is further processed to remove impurities and to control the particle si

Choi et al., (2006) evaluated the high-strength lightweight self-compacting concrete (HLSCC) manufactured by Nan-Su, of which the main factor PF of its design mixing method has been modified and improved.Turatsinze and Garros (2008) investigated the properties of a Self-Compacting Concrete (SCC) incorporating rubber 
aggregates, obtained by grinding end-of-life tyres, as a partial replacement for natural aggregates.M. Hunger et al., (2009) experiments focuses on the direct mixing of microencapsulated PCM with concrete and its influence on the material properties.Grdic et al., (2010) reveled the potential usage of coarse recycled aggregate obtained from crushed concrete for making of self-compacting concrete. The study also focused on its ecological value and issue of the waste disposal sites created by the demolition of old structures.Barbhuiya (2011) studied the utilization of an alternative material, dolomite powder for the production of SCC. The test results indicated that it is possible to manufacture SCC using fly ash and dolomite powder. Dehwah (2012) investigated the mechanical properties of self-compacting concrete (SCC) prepared using quarry dust powder (QDP), silica fume (SF) plus QDP or only fly ash (FA), Experiments were conducted to assess the proportions of QDP, SF+QDP or F A required for producing SCC meeting the flow criteria. In this study SCC specimens were prepared and tested for compressive strength, pulse velocity, split tensile strength and flexural strength. The results revealed that compressive strength and pulse velocity in all SCC specimens increased with age. The compressive strength and pulse velocity of SCC specimens prepared with only QDP were more than those incorporating SF plus QDP or F A alone. The mechanical properties of SCC incorporating QDP (8-10\%) were found to be equal to or better than those of SCC prepared with either SF plus QDP or F A alone.

\section{OBJECTIVE}

The Objective of this paper is to determine the cube compressive strength .cylindrical specimens for split tensile strength and prism specimens for flexural strength with different ratios of cement, fly ash and silica fume (SCC with Silica)and with different ratio of cement, fly ash and Viscosity Modifying Admixture (VMA)i.e(SCC with VMA)at different ages i.e. 3 days 7 days 28 and comparison with values calculated from non-destructive testing i.e. NDT values.

\section{MATERIALS AND METHODS}

3.1-Properties of Material

In order to achieve the objectives of the present study, an experimental program was planned. The aim of the experiments is to study the properties of the materials used

3.1.1:-Cement:- OPC-43 grade (Vikram Brand), cement was used.

3.1.2:-Fly ash:- Fly ash is a by-product of the combustion of pulverized coal in the thermal power plants.

$\bigcirc \quad$ Sp. Gravity of Fly ash used $=64 / 28.5=2.24$

○ Sp. Surface area of Fly ash used $=3438 \mathrm{~cm} 2 / \mathrm{gm}$ In the experimental study, class F fly ash was used.

3.1.3:-Fine aggregate:- Fine aggregate i.e. is sand of $F M=2.32$ was used

3.1.4:- 20mm Size of coarse aggregate:- Coarse aggregate of $F M=6.92$ was used

3.1.5:-10 mm size of coarse aggregate:- Coarse aggregate of $F M=6.63$ was used.

3.1.6:-V.M.A. Glenium-stream was used successfully as viscosity modifying admixture.

3.1.7:-Silica Fume:- Mean Particle size between 0.1 and 0.2 micron was used Silica

\subsection{8:-Deciding Suitable Mix Proportions for SCC}

Initially, three different mix. proportions were chosen based on the total powder content criteria for making SCC. These 3 mixes were as follows:

Mix $\mathrm{M}_{\mathrm{I}}=$ Cement: Fly ash $=300: 400$

Mix M2 $=$ Cement: Flay ash $=300: 400$

Mix M3 = Cement: Fly ash $=250: 350$

Moreover, silica Fume was taken as $7.5 \%$ by wt. of cement.

Two different types of SCC were made in the laboratory keeping the $\mathrm{w} / \mathrm{b}$ constant throughout the entire experimental work.

The (w/b) was taken as 0.26 by weight and only the S.P./P. ratios were varied in order to get sufficient slump flow diameter.

Type 1 SCC - with micro-silica $•$

Type 2 SCC — without micro-silica(by using VMA) 
Later on, two other mix proportions were selected based on the volume

fraction of fly-ash in total binder content.

It was around 0.60 (in between $0.59-0.63$ )

Mix. M4 = Cement: Fly ash = 275: 370

Mix. M5 = Cement: Fly ash $=275: 325$

To make type 2 -SCC, i.e., SCC without micro-silica or in other words VMAJSCC, Glenium-stream was used as a viscosity modifying admixture.

Type - 1 SCC may be described as silica/SCC and type-2 SCC may be described as VMA/SCC.

\subsection{9:-Tests for strength evaluation}

The following tests were performed on the specimens of self-compacting concrete, in order to asses/evaluate the strength parameters of SCC.

These tests were as follows:

- Compressive strength test

- Split tensile strength

- Flexural strength

The following table shows the sizes of the different specimens adopted.

TABLE -1

\begin{tabular}{|l|l|l|l|}
\hline S.no & Specimen & Size(used) & $\begin{array}{l}\text { No.of samples } \\
\text { used at each age }\end{array}$ \\
\hline 1 & Cube & $100 \times 100$ & 3 \\
\hline 2 & cylinder & $100 \times 200$ & 3 \\
\hline 3 & Prism & $100 \times 100 \times 500$ & 3 \\
\hline
\end{tabular}

IV. TEST RESULTS AND DISCUSSION

4.1:-compressive strength:- The cubes were tested on a 200 tones compression-testing machine.

Result of Compressive Strength Values for Silica/SCC (in MPa)

TABLE-2

\begin{tabular}{|l|l|l|l|l|l|l|}
\hline Sr.no & $\begin{array}{l}\text { Mix } \\
\text { Age(d) }\end{array}$ & $\mathbf{M}_{1}$ & $\mathbf{M}_{2}$ & $\mathbf{M}_{3}$ & $\mathbf{M}_{4}$ & $\mathbf{M}_{5}$ \\
\hline & & $(300 / 350)^{*}$ & $(300 / 400)^{*}$ & $(\mathbf{2 5 0 / 3 5 0}) *$ & $(275 / 370)^{*}$ & $(\mathbf{2 7 5 / 3 2 5})^{*}$ \\
\hline 1 & $\mathbf{3}$ & $\mathbf{2 1 . 3}$ & $\mathbf{2 3 . 6}$ & $\mathbf{8 . 8 3}$ & $\mathbf{1 9 . 6}$ & $\mathbf{1 8 . 5}$ \\
\hline $\mathbf{2}$ & $\mathbf{7}$ & $\mathbf{2 6}$ & $\mathbf{3 5 . 6}$ & $\mathbf{2 3 . 5}$ & $\mathbf{3 3 . 3 3}$ & $\mathbf{3 1 . 2 5}$ \\
\hline 3 & $\mathbf{2 8}$ & $\mathbf{4 5}$ & $\mathbf{4 8}$ & $\mathbf{3 2 . 6}$ & $\mathbf{5 8}$ & $\mathbf{5 2}$ \\
\hline
\end{tabular}

FIG-1

Figures in bracket shows Cement/Fly Ash ratios.

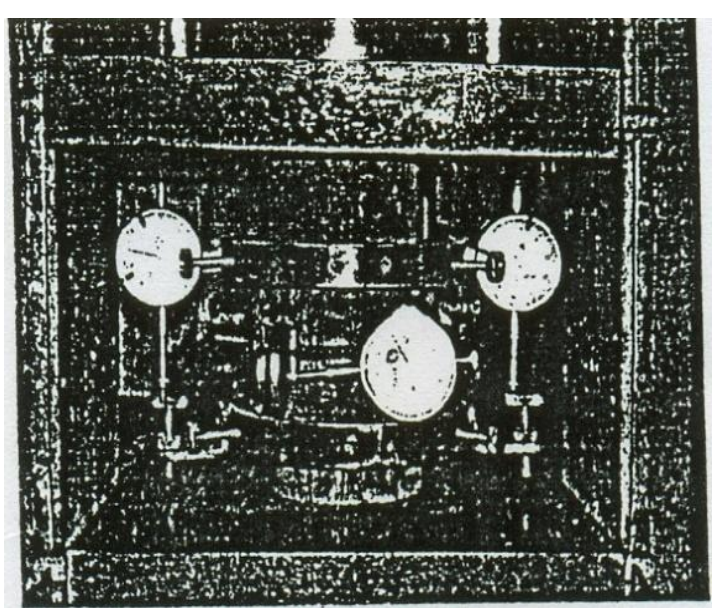

Fig.-1 Setup for Compressometer and Lateral Exteusometer 
Result of Compressive Strength Values for N'MA/SCC (in Ml'a)

TABLE-3

\begin{tabular}{|l|l|l|l|l|l|l|}
\hline Sr.no & $\begin{array}{l}\text { Mix } \\
\text { Age(d) }\end{array}$ & $M_{1}$ & $M_{2}$ & $M_{3}$ & $M_{4}$ & $M_{5}$ \\
\hline & & $(300 / 350)^{*}$ & $(300 / 400)^{*}$ & $(250 / 350)^{*}$ & $(275 / 370)^{*}$ & $(\mathbf{2 7 5 / 3 2 5})^{*}$ \\
\hline 1 & $\mathbf{3}$ & $\mathbf{2 0 . 6 6}$ & $\mathbf{1 2 . 0}$ & $\mathbf{1 3 . 7 5}$ & $\mathbf{1 9 . 6 6}$ & $\mathbf{1 7 . 5}$ \\
\hline $\mathbf{2}$ & $\mathbf{7}$ & $\mathbf{2 8 . 6 6}$ & $\mathbf{1 7 . 0}$ & $\mathbf{1 7 . 2}$ & $\mathbf{3 1 . 2}$ & $\mathbf{3 1 . 5}$ \\
\hline $\mathbf{3}$ & $\mathbf{2 8}$ & $\mathbf{5 4 . 0}$ & $\mathbf{4 0 . 7 5}$ & $\mathbf{3 6 . 0}$ & $\mathbf{5 5 . 0}$ & $\mathbf{5 8 . 5}$ \\
\hline
\end{tabular}

\section{2:-Split Tensile Strength}

Cylindrical specimens were placed horizontally between the loading surfaces of compression testing machine and the load is applied until failure of the cylinder, along vertical diameter.

Result of Splitting Test for Silica/SCC (in MPa)

Table-4

\begin{tabular}{|c|c|c|c|c|c|c|}
\hline Sr.no & $\begin{array}{l}\text { Mix } \\
\operatorname{Age}(d)\end{array}$ & $\mathbf{M}_{1}$ & $\mathbf{M}_{2}$ & $\mathbf{M}_{3}$ & $\mathbf{M}_{4}$ & $\mathbf{M}_{5}$ \\
\hline & & $(300 / 350)^{*}$ & $(300 / 400) *$ & $(250 / 350)^{*}$ & $(275 / 370) *$ & $(275 / 325)^{*}$ \\
\hline 1 & 3 & 1.8 & 1.9 & 0.84 & 1.25 & 1.22 \\
\hline 2 & 7 & 2.1 & 3.34 & 1.96 & 1.75 & 1.87 \\
\hline 3 & 28 & 3.45 & 4.03 & 3.18 & 3.2 & 4.15 \\
\hline
\end{tabular}

Result of Splitting Test for VMAJSCC (in MPa).

Table-5

\begin{tabular}{|l|l|l|l|l|l|l|}
\hline Sr.no & $\begin{array}{l}\text { Mix } \\
\text { Age(d) }\end{array}$ & $M_{1}$ & $M_{2}$ & $M_{3}$ & $M_{4}$ & $M_{5}$ \\
\hline & & $(300 / 350) *$ & $(300 / 400) *$ & $(250 / 350)^{*}$ & $(275 / 370)^{*}$ & $(275 / 325)^{*}$ \\
\hline 1 & 3 & 1.01 & 0.93 & 1.09 & 1.01 & 1.33 \\
\hline 2 & 7 & 1.48 & 1.33 & 1.4 & 1.87 & 2.1 \\
\hline 3 & 28 & 3.58 & 3.12 & 2.26 & 3.43 & 3.4 \\
\hline
\end{tabular}

\section{3:- Flexural Strength}

The flexural strength of the specimen is expressed as the modulus of rupture $f \pi$ which if 'a' equals the distance between the line of fracture and the nearer support, measured on the center line of the tensile side of the specimen, in $\mathrm{cm}$, is calculated nearest to $0.05 \mathrm{MPa}$ as follows:

Results of the Flexural strength for Silica/SCC (in MPa)

TABLE -6

\begin{tabular}{|l|l|l|l|l|l|l|}
\hline Sr.no & $\begin{array}{l}\text { Mix } \\
\text { Age(d) }\end{array}$ & $\mathbf{M}_{1}$ & $\mathrm{M}_{2}$ & $\mathrm{M}_{3}$ & $\mathrm{M}_{4}$ & $\mathrm{M}_{5}$ \\
\hline & & $(300 / 350)$ & $(300 / 400)$ & $(250 / 350)$ & $(275 / 370)$ & $(275 / 325)$ \\
\hline 1 & 28 & 7.10 & 6.84 & 6.25 & 7.01 & 8.95 \\
\hline 2 & 56 & 7.31 & 7.6 & 6.92 & - & - \\
\hline 3 & 128 & 8.50 & 8.16 & - & - & - \\
\hline
\end{tabular}

Results of the flexural strength for VMA/SCC (in MPa)

\section{TABLE- 7}

\begin{tabular}{|l|l|l|l|l|l|l|}
\hline Sr.no & $\begin{array}{l}\text { Mix } \\
\text { Age(d) }\end{array}$ & $\mathrm{M}_{1}$ & $\mathrm{M}_{2}$ & $\mathrm{M}_{3}$ & $\mathrm{M}_{4}$ & $\mathrm{M}_{5}$ \\
\hline & & $(300 / 350)$ & $(300 / 400)$ & $(250 / 350)$ & $(275 / 370)$ & $(275 / 325)$ \\
\hline 1 & $28 \mathrm{~d}$ & 6.22 & 6.62 & 4.81 & 6.62 & 7.6 \\
\hline
\end{tabular}

\section{4:- Ultrasonic Pulse Velocity}

Ultrasonic pulse velocity values were experimentally obtained for cube specimens of different mixes of both Silica/SCC and VMA/SCC, but only for mix M4 and Mix M5 of Silica/SCC as well as of VMA/SCC, UPV values were determined at 3d, 7d, $28 \mathrm{~d}$ and 56 days age.Moreover, U.P.V. values for mixes M1, M2 and M3 were determined at the age of 28 days age. U.P.V. Values for VMA/SCC (in Km/Sec.) 
U.P.V. Values for Silica/SCC and for VMAJSCC (in Km/Sec.)

\begin{tabular}{|l|l|l|l|l|}
\hline S.No. & $\begin{array}{l}\text { Type } \\
\text { SCC }\end{array}$ & \multicolumn{1}{|c|}{ Tix ABLE-8 } & \multicolumn{1}{|c|}{ M4 } & M5 \\
& & & \\
\hline $\mathbf{1}$ & Silica/SCC & 3 & 3.75 & \\
& & 7 & 3.94 & 3.77 \\
& & 28 & 4.52 & 4.24 \\
& & 3 & 3.89 & 4.46 \\
\hline 2 & VMA/SCC & 3 & 4.098 & 4.05 \\
& & 28 & 4.50 & 4.29 \\
& & & & 4.50 \\
\hline
\end{tabular}

\section{5:-Rebound Hammer Values}

Similar to the U.P.V. testing, which was performed for M4 and M5 mixes for both type of SCC at 3d, 7d, 28(1 and 56 days, Rebound Hammer values were also obtained for the same age period and for the same mixes.

\section{FIG-7}

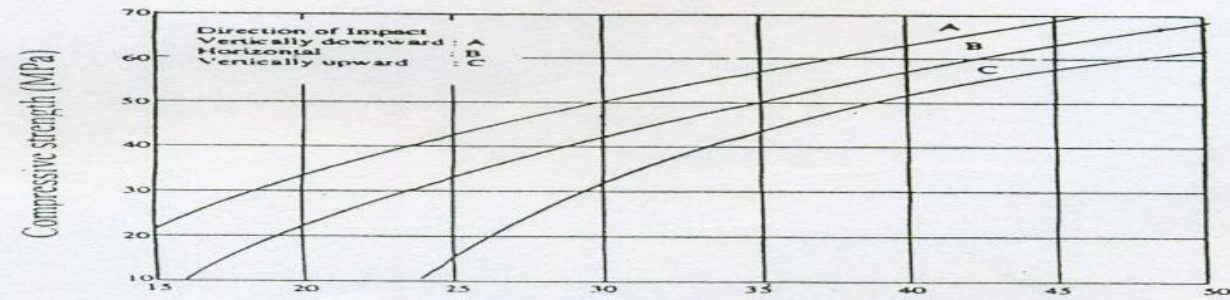

\begin{tabular}{|l|l|l|l|l|l|l|l|}
\hline S.NO & MiX & Mi & PCS* & M2 & PCS* & M3 & PCS* \\
& Age (d) & $(300 / 350)$ & Values & $(300 / 400)$ & Values & $(250 / 350)$ & Values \\
\hline 1 & 28 & 34 & 49 & 42 & 58 & 39 & 56.5 \\
\hline
\end{tabular}

Rebound Hammer values for VMA/SCC Table No. 9

Fig. 7: Graph for Comp. Strength vs. Rebound no.

*PC S values stand for probable compressive strength values (in MPa) based on Rebound Number

Rebound Hammer Values for Silica/SCC and for VMA/SCC TABLE- 10

\begin{tabular}{|l|l|l|l|l|l|l|}
\hline \multirow{2}{*}{ Sr.No. } & Type of SSC & Mix & M4 & $\begin{array}{l}\text { PCS } \\
\text { Values }\end{array}$ & M5 & $\begin{array}{l}\text { PCS } \\
\text { Values }\end{array}$ \\
\hline 1 & Silica/SCC & 3 & 30 & 42 &.- & 43 \\
& & 7 & 33 & 47 & 39 & 57 \\
& & 28 & 42 & 58 & 45 & 63 \\
\hline 2 & VMA/SCC & 3 & 30 & 42 & 28 & 41 \\
& & 7 & 35 & 50 & 41 & 58 \\
& & 28 & 45 & 63 & 47 & 66 \\
\hline
\end{tabular}

\section{6:- Test Results at Fresh Stage}

Tests at fresh stage for SCC include $\mathrm{W} / \mathrm{b}$ ratio, $\mathrm{W} / \mathrm{p}$ ratio (by vol.), S.P./P ratio and flow ability data viz, slump flow diameter (mm.), segregation index (in \%age), U-box test etc. As far as flow ability data for SCC is concerned, it is to be noted that slump flow diameter should be more than $600 \mathrm{~mm}$, segregation index value should be lower than $15 \%$ and for U-box test, the filling height in both the chambers should be nearly equal. 
TABLE- 11 (For. Silica/SCC)

\begin{tabular}{|l|ll|l|l|l|l|l|}
\hline S. No. & $\begin{array}{l}\text { Type of Mix } \\
\text { ( C./Fly ash } \\
\text { ratio) }\end{array}$ & $\begin{array}{l}\text { W/b } \\
\text { ratio } \\
\text { (by wt.) }\end{array}$ & $\begin{array}{l}\text { W/p ratio } \\
\text { (by vol.) }\end{array}$ & $\begin{array}{l}\text { S.P./P. } \\
\text { ratio }\end{array}$ & $\begin{array}{l}\text { Slump } \\
\text { flow dia. } \\
\text { (mm) }\end{array}$ & $\begin{array}{l}\text { Segregation } \\
\text { index }\end{array}$ & $\begin{array}{l}\text { U-Box } \\
\text { test } \\
\text { results }\end{array}$ \\
\hline 1 & M1 (300/350) & 0.26 & 0.66 & $1 \%$ & 630 & $4.52 \%$ & Satisfied \\
\hline 2 & M2 (300/400) & 0.26 & 0.66 & $0.54 \%$ & 625 & $4.87 \%$ & do \\
\hline 3 & M3 (250/350) & 0.26 & 0.66 & $2.3 \%$ & 632 & $6.2 \%$ & do \\
\hline 4 & M4 (275/370) & 0.26 & 0.66 & $\mathbf{0 . 8 8 \%}$ & 610 & $4.4 \%$ & do \\
\hline 5 & M5 (275/3251_0.26 & $0.66 \_-$ & $2.2 \%$ & 612 & $5.33 \%$ & do \\
\hline
\end{tabular}

Note: (Silica content was kept constant for all the mixes. It was taken as $7.5 \%$ by wt. ofcement)

TABLE- 12 (For VMA/SCC)

\begin{tabular}{|l|l|l|l|l|l|l|l|}
\hline S. No. & $\begin{array}{l}\text { Type of Mix } \\
\text { (C./Fly ash } \\
\text { ratio) }\end{array}$ & $\begin{array}{l}\text { W/b } \\
\text { ratio } \\
\text { (by wt.) }\end{array}$ & $\begin{array}{l}\text { (by vol.) } \\
\text { (by ratio }\end{array}$ & ratio & $\begin{array}{l}\text { Segregation } \\
\text { index } \\
\text { dia. }\end{array}$ & $\begin{array}{l}\text { flow } \\
\text { test } \\
\text { results }\end{array}$ \\
\hline I & M1 (300/350) & 0.26 & 0.67 & $0.7 \%$ & 640 & $7.2 \%$ & Satisfied \\
\hline 2 & M2(300/400) & 0.26 & 0.66 & $\mathbf{0 . 3 6 \%}$ & $\mathbf{6 2 5}$ & $\mathbf{1 1 . 4 \%}$ & do \\
\hline 3 &, & 0.26 & 0.66 & $1.6 \%$ & 610 & $6.7 \%$ & do \\
\hline 4 & M4 (275/370) & 0.26 & 0.66 & $0.54 \%$ & 622 & $13.96 \%$ & do \\
\hline 5 & M5 (275/325) & 0.26 & 0.67 & $1.43 \%$ & 602 & $2.5 \%$ & do \\
\hline
\end{tabular}

Note: For making VMA type SCC, the same content of VMA (G. stream) was added as superplasticiscer Glcnium-51.

\section{COST}

The concrete become economical by using silica Fume and Fly ash in concrete mixes .The Silica fume and Fly ash are industrial waste they are available in market at free of cost and transportation charges are involved .it is observed that the cost of concrete decreases with the increase in percentage of Fly ash and Silica fume .

\section{CONCLUSION}

1. Fly ash is not only helpful as a replacement of cement, a costly material, but also it is helpful in increasing the flow of concrete mix so as to fulfill the SCC criteria.

2. If a comparison is made between the two types of SCC viz., SCC with micro-silica and SCC without micro-silica (using VMA), it was observed that VMA/SCC provides better surface finish as compared to Silica/SCC.

3. A successful SCC mix can also be developed with w/p ratio (by volume) less than 0.8 .

4. Silica fume was found to control the segregation.

5. Based on the experimental data obtained for Modulus of Elasticity and Poisson's ratio, it can be stated that these values falls on the lower side for SCC as compared to normal concrete for the similar strength.

6. The stress-strain curves for different mixes clearly depict that strain values. for VMA/SCC were on the higher side as compared to strain values for Silica/SCC. Strain values for VMAJSCC were upto 0.0065 whereas for Silica/SCC, it was upto 0.0038.

7. Compressive strength curve pattern shows that there is uniform increase of compressive strength values for VMAJSCC to that Sili ca/SCC.

8. Early age compressive strength (at 3 days and 7 days) of Silica/SCC was found more then VMA/SCC. Making 7 days compressive strength consideration, Silica/SCC was found in between 23.5 to $35.6 \mathrm{MPa}$ whereas for VMA/SCC, it was found in between 17.0 to $31.5 \mathrm{MPa}$.

9. The U.P.V. values were found to have good correlation with the compressive strength values of self-compacting concrete. This fact was evident on the basis that U.P.V. values were found uniformly increasing as the quality of concrete increases.

10. Rebound hammer values were not found to have good correlation with compressive strength values of selfcompacting concrete. 


\section{REFRENCES}

[1] Proceedings of International Workshop on Self-compacting Concrete, 23-26 Aug. 1998, Kochi University of Technology, Kochi, Japan. (pp. 183-186).

[2] Khayat, Kamal H., et al., "Importance of Aggregate Packing Density on Workability of Self-compacting Concrete", First North American Conference on the Design and use of SCC, Nov. 2002. (pp 55-58).

[3] Specifications and Guidelines for Self-compacting Concrete, Feb. 2002, EFNARC, Association House. (www.efnarc.org), (pp.9-30).

[4] Choi, Y.W.; Kim, Y.J.; Shin, H.C. and Moon, H.Y., "An experimental research on the fluidity and mechanical properties of high-strength lightweight self-compacting concrete", Cement and Concrete Research, 36, 2006. (pp. 1595-1602).

[5] Change Materials", Cement \& Concrete Composites, 31, 2009. [14] (pp. 731-743).

[6] Turatsinze, A. and Garros, M. "On the modulus of elasticity and strain capacity of Self-Compacting Concrete incorporating rubber aggregates", Resources, Conservation and Recycling, 52, 2008. (pp. 1209-1215).

[7] M. Hunger, .; Entrop, A.G.; Mandilaras, I.; Brouwers, H.J.H. and Founti, M., "The behavior of self-compacting concrete containing micro-encapsulated Phase Change Materials", Cement \& Concrete Composites, 31, 2009. (pp. 731-743).

[8] Kou, S.C. and Poon, C.S. , " [13] Properties of self-compacting concrete prepared with recycled glass aggregate", Cement \& Concrete Composites, 31, 2009. (pp.107113).

[9] Grdic, Z.J.; Toplicic-Curcic, G.A.; Despotovic, I.M. and Ristic, N.S. "Properties of self-compacting concrete prepared with coarse recycled concrete aggregate", Construction and Building Materials, 24, 2010. (pp.1129-1133).

[10] Najim, K.B. and Hall, M.R., [16] "A review of the fresh/hardened properties and applications for plain- (PRC) and self-compacting rubberised concrete (SCRC)", Construction and Building Materials, 24, 2010, (pp. 2043-2051).

[11] Salim Barbhuiya "Effects of fly ash and dolomite powder on the properties of selfcompacting concrete", Construction and Building Materials, 25, 2011. (pp. 3301$3305)$.

[12] Corinaldesi, V. and Moriconi, G [22]., "The role of industrial by-products in selfcompacting concrete", Construction and Building Materials, 25, 2011. (pp. 3181$3186)$.

[13] Dehwah, H.A.F., [34] "Mechanical properties of self-compacting concrete incorporating quarry dust powder, silica fume or fly ash", Construction and Building Materials, 26, 2012. (pp. 547-551).

[14] Siddique, R.; Aggarwal, P. and Aggarwal, Y., "Influence of water/powder ratio on strength properties of self-compacting concrete containing coal fly ash and bottom ash", Construction and Building Materials, 29, 2012. (pp. 73-81).

[15] Uysal, M.; Yilmaz, K. and Ipek, M., [32] "Properties and behavior of selfcompacting concrete produced with GBFS and FA additives subjected to high temperatures", Construction and Building Materials, 28, 2012. (pp. 321-326).

[16] Dehwah, H.A.F., (34) "Mechanical properties of self compacting concrete incorporating quarry dust powder, silica fume or fly ash", Construction and Building Materials, 26, 2012. (pp.547-551) 